\title{
Thermocapillary breakdown of a horizontal spot-heated liquid layer
}

\author{
Serafim Spesivtsev ${ }^{1,2, a}$, Yuriy Lyulin ${ }^{1,3}$ \\ ${ }^{1}$ Institute of Thermophysics, 1, Lavrentiev Ave., 630090, Novosibirsk, Russia \\ ${ }^{2}$ Novosibirsk State University, 2, Pirogov Ave., 630090, Novosibirsk, Russia \\ ${ }^{3}$ Tomsk Polytechnic University, 30, Lenina Ave, Tomsk, 634050, Russia
}

\begin{abstract}
Thermocapillary breakdown of thin $(0.3-0.7 \mathrm{~mm})$ horizontal layers of liquid (ethanol) when heated from a localized hot spot was investigated experimentally. The effects of layer thickness and the surface properties of the substrates on the breakdown dynamics were studied. Visualization and control of the liquid layer were carried out using schlieren and shadowgraphy techniques. Main steps of the breakdown process were determined and average velocity of the dry spot formation was measured. Significant influence of the substrate properties on breakdown dynamics has been found. It was shown that one of the main factors affecting the dynamics of layer breakdown and the formation of dry spots in the heating area besides the thermocapillary effect is evaporation.
\end{abstract}

\section{Introduction}

Study of heat transfer from a local heat source becomes one of the most important problems in thermophysics. The problem is closely connected to the cooling of microelectronic equipment [1]. Permanent consumption of electricity by the device inevitably leads to increasing the microprocessor temperature and degradation of its performance and reliability. Continuous development and complication of microchip structure produce nonuniform heat flux distribution on the chip surface. Heat flux density in some regions is much higher than the chip average [2], of the order of $1 \mathrm{~kW} / \mathrm{cm}^{2}$. These specific regions called "hot spots" could have size from several hundred microns to 1-2 millimeters. However, using special localized cooling it is possible to produce large performance gains in microprocessors. Nowadays, there are several effective techniques for cooling of local hot spots such as spray cooling, boiling in microchannels, thermoelectric coolers. One of the promising methods for removing such high heat fluxes from a spotted heat source is technology based on evaporation of a thin liquid layer. Dynamics of evaporation essentially depends on the conditions in the layer [3]. In particular, the breakdown of liquid layer leads to dramatic decreasing of heat transfer from a spotted heat source [4]. Processes of liquid layer rupture are actively studied experimentally [46] and theoretically in the present time [7-9]. The goal of the present work is to study using schlieren technique the breakdown dynamics of a horizontal evaporating liquid layer when heated from a localized hot spot.

\footnotetext{
${ }^{\text {a }}$ Corresponding author: simafir94@gmail.com
} 


\section{Experimental setup}

Experiments were conducted on the setup shown in Fig. 1. The working fluid is supplied to the test cell with the help of the syringe pump and a horizontal liquid layer is formed. The thickness of liquid layer is varied from 300 to $700 \mu \mathrm{m}$. The layer of liquid is opened to the atmosphere and maintained on the surface of the working area using sharp edge on the substrate perimeter. Spot heating of the horizontal liquid layer takes place in the center of the substrate. The test cell consists of caprolon base, metallic substrate and the heating element. The caprolon base has a special cut on the upper side for installation of the substrate and a central through hole with a diameter of $1.6 \mathrm{~mm}$. The substrate is made of stainless steel and has a diameter of $50 \mathrm{~mm}$ and a thickness of $1 \mathrm{~mm}$. In the center of the substrate is a closed hole with a diameter of $1.6 \mathrm{~mm}$ and a height of $0.8 \mathrm{~mm}$. The heating element is made of brass and has a round tip with a diameter of $1.6 \mathrm{~mm}$ and a height of $3 \mathrm{~mm}$. It is tightly inserted into the closed hole of the substrate through the caprolon base. Thermal paste is used for better thermal contact between the heater tip and the substrate. The distance between the tip and the upper side of substrate is $0.2 \mathrm{~mm}$. The power of heating element is controlled by the power supply. Insulating material is located on the underside of the heater to minimize heat losses. Temperature in the test cell is measured by thermocouples (type $\mathrm{K}$ ) with an accuracy of $0.1^{\circ} \mathrm{C}$. Location of the thermocouples is shown in Fig. 1. Relative humidity and atmosphere temperature are measured using the thermohygrometer Testo 645 with an accuracy of $2 \%$ and $0.1^{\circ} \mathrm{C}$, respectively.

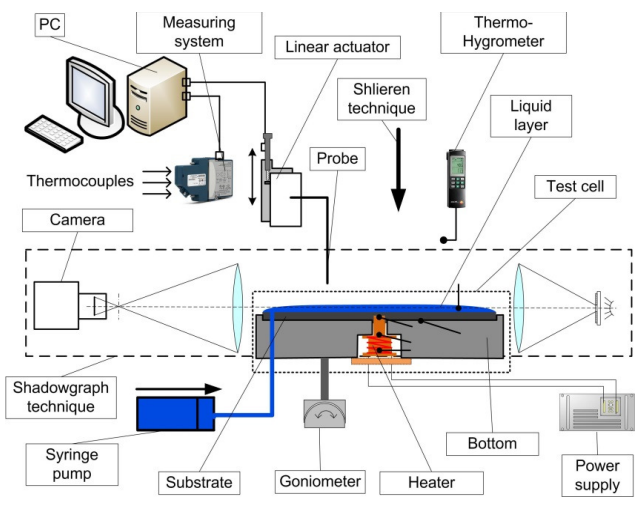

Figure 1. Scheme of the experimental setup.

The heat flux density is determined by measuring the temperature difference between two different sections along the heater tip. The height of the horizontal liquid layer is maintained in constant position during the all experiment. The probe with a diameter of $100 \mu \mathrm{m}$ is installed at a required distance from the substrate surface. With the help of high-precision syringe pump the flow rate is chosen for providing a constant layer thickness, taking into account the evaporation. In the experiment the layer surface is maintained at a distance of 3-5 $\mu \mathrm{m}$ below the probe. If the height of the liquid layer is increased upper the required one the liquid meniscus is formed due to the contact the probe and liquid surface. The event of the contact is instantly visualized on the camera. Precise linear actuator and shadowgraph technique are used in order to determine the position of the probe. The probe moves in range of $5 \mathrm{~mm}$ by steps of $1 \mu \mathrm{m}$. Linear actuator is controlled from personal computer and by special software. Observation of the layer surface and the probe is carried out using video camera of shadowgraph technique with a resolution $2592 \times 1944$ pixels and a field of view of $4.3 \times 5.8 \mathrm{~mm}$. For visualization the deformation of the surface and recording the layer breakdown dynamics schlieren technique with Phantom 3798M high-speed camera was used (at 2500 frames per second the resolution is $256 \times 256$ pixels and the field of view is $7 \times 7 \mathrm{~mm}$ ). The test cell was installed in a horizontal position with the help of two-axis goniometer. Equilibrium contact angle of the substrate surface was defined by Young-Laplace method [10] at room temperature of $25 \pm 2^{\circ} \mathrm{C}$. The values of the contact angle is $\theta_{1}=8 \pm 1^{\circ}$ for smooth steel substrate and $\theta_{2}=6 \pm 1^{\circ}$ for rough steel substrate. Profilometer "Micro Measure 3D station" was used for measuring the roughness of substrates. 
Average values of the roughness are $\mathrm{R}_{\mathrm{a} 1}=0.037 \mu \mathrm{m}$ and $\mathrm{R}_{\mathrm{a} 2}=0.327 \mu \mathrm{m}$ for smooth and rough steel substrate, respectively.

\section{Results and discussion}

Experiments were conducted at atmospheric pressure, temperature and relative humidity of $28 \pm 2^{\circ} \mathrm{C}$ and $25 \pm 3 \%$, respectively. Layer thickness was ranged from 300 to $700 \mu \mathrm{m}$. Ethanol (95\%) was used as a working fluid. Heater temperature range was $20-105^{\circ} \mathrm{C}$. Heat flux density was varied from 0 to 95 $\mathrm{W} / \mathrm{cm}^{2}$. Injection liquid flow rate was up to $200 \mu \mathrm{l} / \mathrm{min}$. During the experiment heat flux is increased up to a critical value at which the liquid layer ruptures. At this moment heating process is stopped to prevent the failure of heating element.

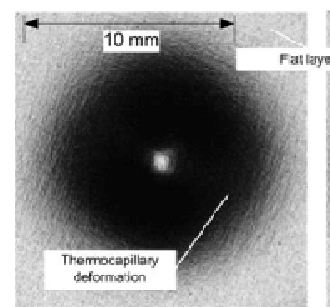

(a)

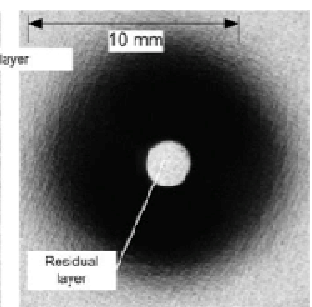

(b)

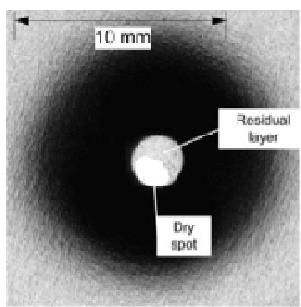

(c)

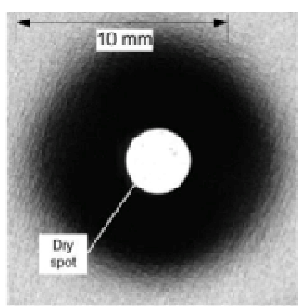

(d)

Figure 2. Visualization of breakdown dynamics and formation of the dry spots.

It was found that breakdown process consists of several steps. At the beginning, thinning of the liquid layer over the heating area (Fig. 2a) due to the effect of thermocapillary forces [11, 12] and evaporation is observed. Further thinning leads to the formation of residual liquid layer in the area of the local heating, Fig. 2b. Then the residual layer evaporates until its thickness reaches the critical and breakdown of the liquid layer occurs, Fig. 2c, [4, 5]. After the breakdown the whole area of the local heating rapidly dries and quite symmetrical circular dry spot is formed, Fig. 2 d.

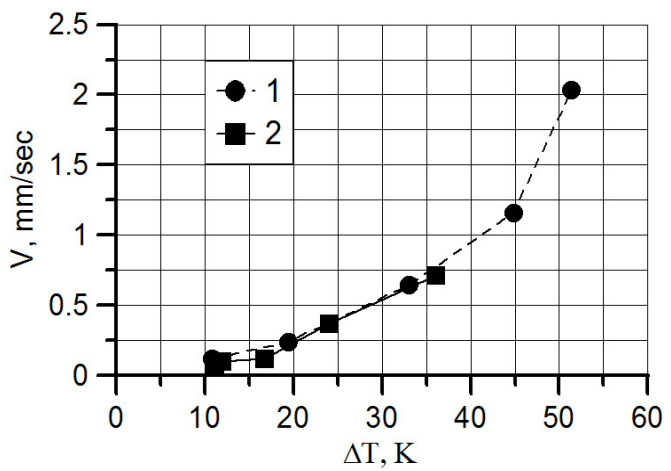

Figure 3. Dependence of the dry spot velocity on the radial temperature drop. 1- smooth substrate, 2- rough substrate.

Dependence of the characteristic velocity of dry spot formation on the radial temperature drop is shown in Fig. 3. The difference $\Delta \mathrm{T}$ is taken between the heater temperature and the temperature at a distance of $15 \mathrm{~mm}$ from the center. The temperature values were measured at the moment of layer breakdown for different layer thickness (from 300 to $700 \mu \mathrm{m}$ ) for each substrate. The average propagation velocity of dry spot was determined as the ratio of the dry spot diameter to the time of dry spot formation. The time of dry spot formation is calculated from the moment of breakdown to the complete evaporation of residual liquid layer. For rough steel substrate the time of dry spot formation varies from 1.39 to 7.85 seconds depending on the layer thickness. For smooth substrate the time range is from 0.67 to 7.88 seconds. It was found that the dry spots velocity increases with the radial 
temperature drop. Temperature in the center of substrate increases and more intense evaporation of residual layer takes place. Thus, one of the main factors influencing the residual layer breakdown and the heating region draining is evaporation.

Effect of the surface properties on dynamics of layer breakdown was found. Dry spots were arisen in various points simultaneously and dewetting process was observed on the rough substrate, Fig. 4a. In case of the smooth substrate the residual layer breakdown occurs in one point, Fig. $4 \mathrm{~b}$.

(a)

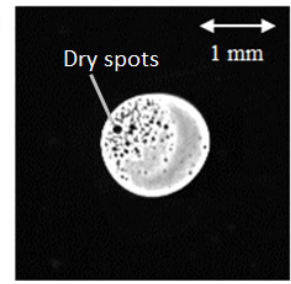

(b)

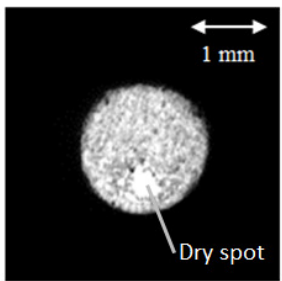

Figure 4. Effect of the surface properties on breakdown dynamics (layer thickness $700 \mu \mathrm{m}$ ): a - rough substrate, $\mathrm{R}_{\mathrm{a}}=0.327 \mu \mathrm{m} ; \mathrm{b}-$ smooth substrate, $\mathrm{R}_{\mathrm{a}}=0.037 \mu \mathrm{m}$.

\section{Conclusions}

Influences of the layer thickness, intensity of heating and type of substrate on the breakdown dynamics of liquid layer were studied. The existence of residual liquid layer over the heating area before the breakdown has been proved. Velocity of dry spots formation increased when the local heating intensity is increased. One of the main factors that influence the breakdown of residual liquid layer and dry spot formation is evaporation. Significant influence of the surface properties on breakdown dynamics of liquid layer has been found. In case of the rough substrate dry spots were arisen in various points simultaneously and dewetting process was observed. For the smooth surface the residual layer ruptures in one place.

The study was financially supported by the Russian Science Foundation (Project 14-19-01755).

\section{References}

1. A. Bar-Cohen, P. Wang, J. Heat Transfer 134, 5 (2012)

2. R. Mahajan, C. Chiu, G. Chrysler, Proceedings of the IEEE 94, 8 (2006)

3. A.A. Fedorets, I.V. Marchuk, O.A. Kabov, Interfacial Phenomena and Heat Transfer 1, 1 (2013)

4. Yu.V. Lyulin, S.E. Spesivtsev, I.V. Marchuk, O.A. Kabov, Technical Physics Letters 41, 11, 1034-1037 (2015)

5. D.V. Zaitsev, D.A. Rodionov, O.A. Kabov, Microgravity Science and Technology, 19, 100 (2007)

6. D.V. Zaitsev, O.A. Kabov, Microgravity Science and Technology, 19, 174 (2007)

7. V. S. Ajaev, Interfacial Phenomena and Heat Transfer 1, 1 (2013)

8. M. B. Williams and S. H. Davis, J. Colloid Interface Sci. 90 (1982)

9. J. P. Burelbach, S. G. Bankoff and S. H. Davis, Phys. Fluids A 2, 322-333 (1990)

10. I.V. Marchuk, V.V. Cheverda, P.A. Strizhak, and O.A. Kabov, Thermophysics and Aeromechanics 22, 3 (2015)

11. I. V. Marchuk, Journal Engineering of Thermophysics 18 (2009)

12. I.V. Marchuk, Journal Engineering of Thermophysics 24 (2015) 